Review

\title{
Wireless Sensor Networks for Oceanographic Monitoring: A Systematic Review
}

\section{Cristina Albaladejo, Pedro Sánchez *, Andrés Iborra, Fulgencio Soto, Juan A. López and Roque Torres}

DSIE, Technical University of Cartagena, Campus Muralla del Mar s/n, Cartagena, E-30202, Spain; E-Mails: cristina.albaladejo@upct.es (C.A.); andres.iborra@upct.es (A.I.); pencho.soto@upct.es (F.S.); jantonio.lopez@upct.es (J.L.); roque.torres@upct.es (R.T.)

* Author to whom correspondence should be addressed; E-Mail: Pedro.Sanchez@ upct.es; Tel. +34-968-325654; Fax: +34-968-325345.

Received: 11 June 2010; in revised form: 29 June 2010 / Accepted: 1 July 2010 /

Published: 19 July 2010

\begin{abstract}
Monitoring of the marine environment has come to be a field of scientific interest in the last ten years. The instruments used in this work have ranged from small-scale sensor networks to complex observation systems. Among small-scale networks, Wireless Sensor Networks (WSNs) are a highly attractive solution in that they are easy to deploy, operate and dismantle and are relatively inexpensive. The aim of this paper is to identify, appraise, select and synthesize all high quality research evidence relevant to the use of WSNs in oceanographic monitoring. The literature is systematically reviewed to offer an overview of the present state of this field of study and identify the principal resources that have been used to implement networks of this kind. Finally, this article details the challenges and difficulties that have to be overcome if these networks are to be successfully deployed.
\end{abstract}

Keywords: systematic review; wireless sensor networks; oceanography

\section{Introduction}

Coastal marine systems are particularly vulnerable to the effects of human activity attendant on industrial, tourist and urban development. Information and communications technologies offer new solutions for monitoring such ecosystems in real time. In response to this demand for technology, the 
last ten years have seen the emergence of various initiatives, from simple case studies to complex coastal observation systems designed to monitor the marine environment. These systems are composed of sensor nodes, frequently wireless, which transmit data to a sink node, in real time, on a number of physical, chemical and/or biological measurements (temperature, $\mathrm{pH}$, dissolved oxygen, salinity, turbidity, phosphates, chlorophyll, etc.).

In this context, Wireless Sensor Networks (WSNs) [1,2] offer a new paradigm for oceanography, as in many other disciplines such as precision agriculture, environmental, engineering, etc. WSNs are a type of autonomous, self-organized ad-hoc Wireless Personal Area Networks (WPAN) composed of tens, hundreds or even thousands of smart low-rate battery-powered sensor nodes (motes). In a WSN, sensor nodes normally consist of a processor, a radio module, a power supply and one or more sensors mounted on the mote itself or connected to it. The processor controls all the node's functions such as access to sensors, control of communications, execution of algorithms, battery saving, energy source management, etc.

The design, implementation and deployment of a WSN for oceanographic applications poses new challenges different to the ones that arise on land, as the impact of the marine environment on the sensor network limits and affects their development. The following are some of the most important differences:

- The marine environment is an aggressive one which requires greater levels of device protection.

- Allowance must be made for movement of nodes caused by tides, waves, vessels, etc.

- Energy consumption is high since it is generally necessary to cover large distances, while communications signals are attenuated due to the fact that the sea is an environment in constant motion.

- The price of the instrumentation is significantly higher than in the case of a land-sited WSN.

- There are added problems in deployment of and access to motes, the need for flotation and mooring devices, possible acts of vandalism, and others.

In spite of all these drawbacks, various case studies of monitoring of marine ecosystems using WSNs can be found in the literature [3-14]. What these solutions have in common is that they are largely designed and implemented ad-hoc (buoys, electronics and software), and oceanographic sensors and some other components are normally the only elements acquired from third parties.

In the scientific literature we can distinguish two broad categories of marine wireless networks depending on the data transmission medium that they use: WSNs based on radio frequency (RF) aerial communications (hereafter called Aerial-WSNs or A-WSNs) and Under-Water Acoustic Sensor Networks (UW-ASNs).

A UW-ASN [15] consists of a variable number of sensors and vehicles that are deployed to perform collaborative monitoring tasks over a given area. In underwater conditions RF does not work well because radio waves propagate only at very low frequencies $(30-300 \mathrm{~Hz})$ and special antennas and a bigger power supply are required. The problems that underwater acoustic networks of this kind pose include: bandwidth is severely limited; propagation delays are five orders of magnitude greater than in terrestrial radio frequency channels; higher bit error rates and temporary losses of connectivity; limited battery power because solar energy cannot be used, and so on. UW-ASNs are the best solution for viable oceanographic monitoring at great depths entailing the use of Autonomous Underwater Vehicles 
(AUVs) equipped with underwater sensors. Underwater networking is a relatively little-explored area although experimentation with underwater communications has been going on for several decades.

A-WSNs [1,16] consist of a set of nodes with scanty power supplies, which moreover communicate with one another by way of low-consumption radio modules. In addition, they have one or more nodes with bigger power supplies which act as sinks. These communicate with a remote station using longer-range connections (via satellite, GPRS, etc.). This type of network should not be confused with the ones in which each node has a large power supply and connects directly to the base station. These are isolated buoys linked to a data collection centre using satellite communications. In this case, since systems incorporate considerable computational capacities, power and communications resources they are not considered as A-WSN.

A-WSNs do not present the problems described above in the case of UW-ASNs, but they do pose other problems; for example, they have to transmit via data cables running from underwater sensors to buoys on the surface. Where these sensors are located at great depths, the problems that arise can also be serious. In short, there is no ideal solution, and the most suitable technology will depend on the particulars of each case.

The purpose of this article, following an introduction to the component elements of an A-WSN for oceanographic monitoring, is to provide an overview of the systems that have been developed in the last ten years based on the deployment of networks of this kind. The study looks basically at the most significant deployments that have been implemented world-wide. The most relevant information was gathered on each one, followed by a comparative and systematic analysis of the different solutions. As a result of that study, we have identified and summarized the main elements used (hw/sw infrastructure) when implementing the different monitoring systems, and their principal features (measurements taken, characteristics of deployment, harvesting systems, etc.).

Section 2 summarizes the general structure of an oceanographic A-WSN and the elements commonly used in implementing the network. Section 3 details the method used in the systematic review. Section 4 summarizes the results of the study. Section 5 presents a discussion of those results. Finally, Section 6 presents the conclusions and details the principal challenges and difficulties entailed in deploying an A-WSN for oceanographic monitoring.

\section{Fundamentals of Aerial Wireless Sensor Networks for Oceanographic Monitoring.}

This section details the various components of an A-WSN network and the resources needed to deploy it for oceanographic monitoring.

\subsection{Sensor Nodes}

Figure 1 details the elements commonly used in the design and implementation of a sensor node. As we can see, it is normal to include a flotation device such as a buoy to keep part of the node out of the water. This out-of-the-water part always includes an antenna for RF transmission, optionally a harvesting system (solar panel, eolic generator, etc.) to supplement the power source, and in some cases one or more external sensors essentially to monitor meteorological data (windspeed, air temperature, atmospheric humidity, etc.). The submerged part of the node is composed of one or more sensors, which may be placed at different depths (sensor strings), a sonde to transmit the data collected 
to the buoy, and finally some means of anchoring the buoy to the seabed in order to prevent it from moving (due to marine currents, wind, waves, etc.).

The mote's electronics include: a module for RF transmissions, a power supply regulation and management system, a set of interfaces for accessing the sensors, a module for amplification, conversion (analog to digital) and multiplexing of the data read from the sensors (surface and underwater), a FLASH-type permanent read/write memory, a clock to act as a timer, scientific instruments (e.g., improved meteorological packages, acoustic recording packages, biological samplers, etc.), and lastly a CPU (microprocessor) to centralize the whole process and implement the user-defined monitoring functions.

Figure 1. General scheme of a sensor node for oceanographic monitoring.

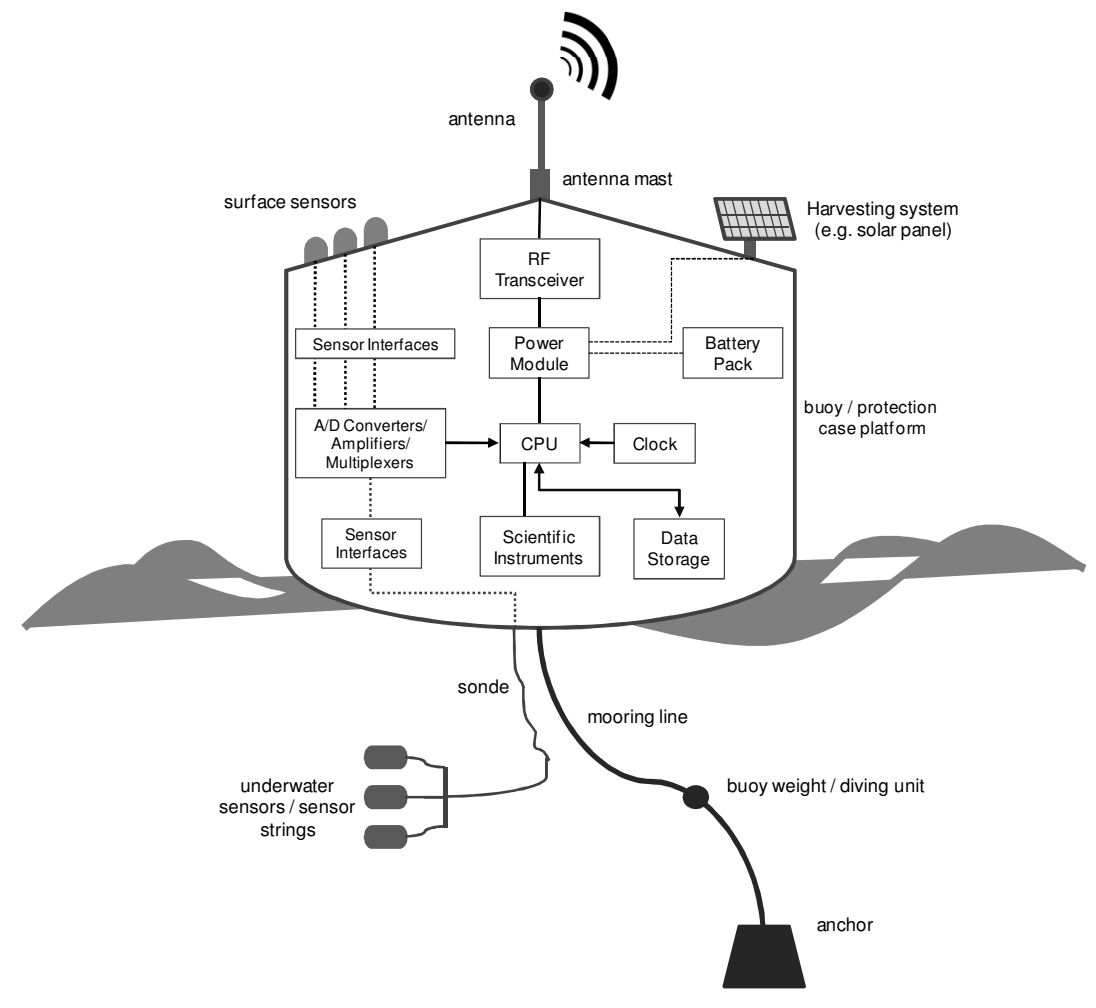

\subsection{A-WSN General Architecture}

Figure 2 shows a general architecture of an A-WSN for oceanographic monitoring. There are two main types for inter-node communication: point-to-point $v s$. multihop. There are almost always one or more nodes that communicate directly with the base station. These act as sinks and may not have a role in the monitoring process.

The differences between deployments are essentially determined by decisions concerning:

(1) the network topology;

(2) the dimensions of the area to be monitored and the number of nodes used in the deployment;

(3) the communication devices/protocols used and the radio frequencies chosen;

(4) facilities for accessing the nodes for repair or removal (maintenance);

(5) the flotation and mooring systems used;

(6) the types of oceanographic sensors considered; 
(7) the tools for monitoring the network developed for real-time visualization of the data gathered; and

(8) the electronics used for autonomous sampling of the requisite parameters and for wireless transmission to a data server.

Figure 2. General structure of an A-WSN for oceanographic monitoring.

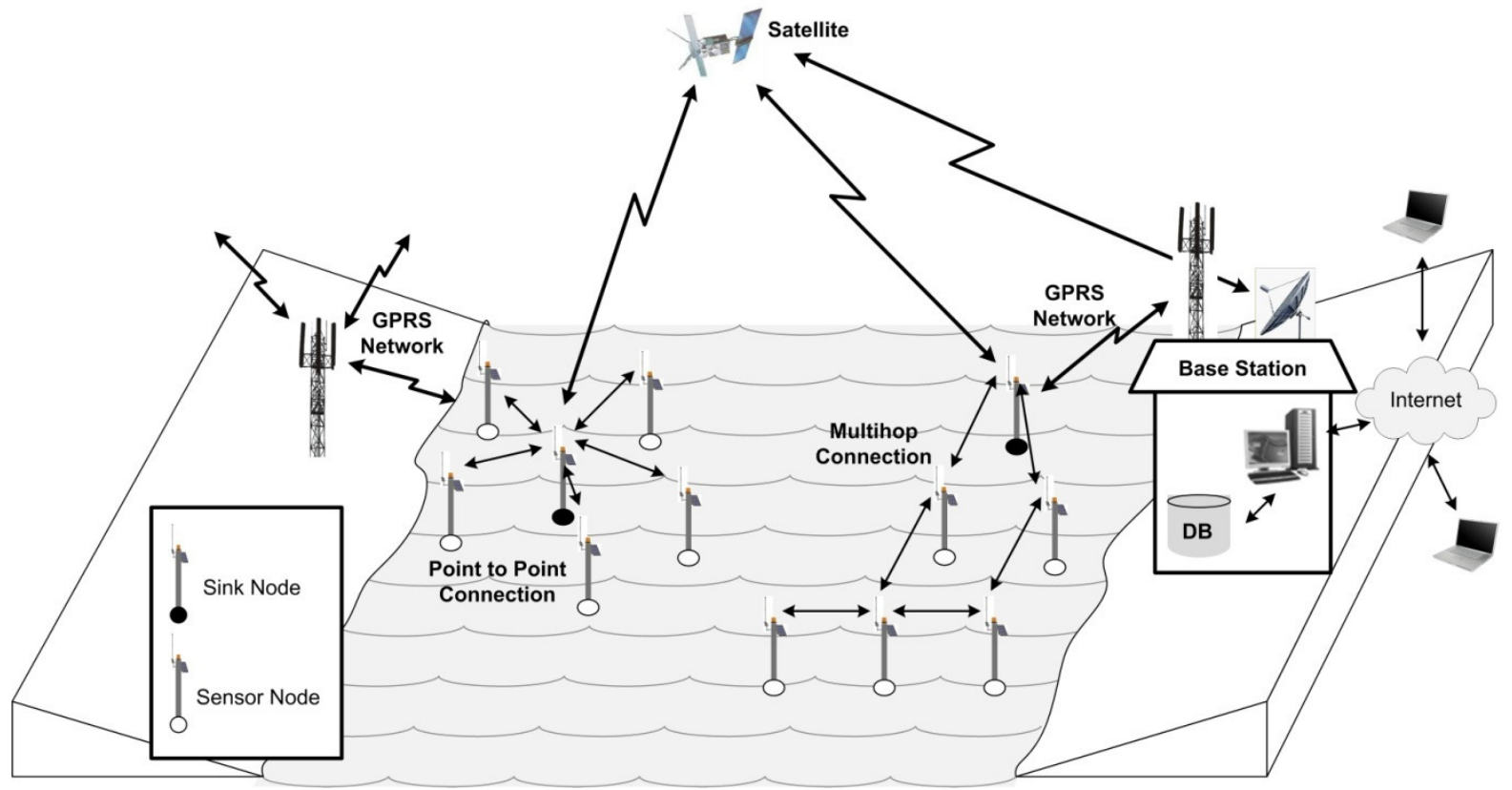

The component elements of an A-WSN are generally common, irrespective of where they are used (wireless sensor nodes, a communications protocol, a monitoring application, etc.). But even so, there are major differences depending on the characteristics of the deployment. One of the most obvious such differences, as we shall see in detail later on, is the type of sensors that are to be used, which will be very specific to the environment it is proposed to monitor and the end in view.

\subsection{Wireless Communications}

Network physical topology and density are entirely application-dependant [17], so before deploying an A-WSN it is necessary to understand the environment in which it will be installed. This implies choosing the most suitable number of nodes and their absolute position inside the area to be monitored. Denser deployments improve data accuracy and provide sensor networks with more energy and better connectivity. However, at the same time a denser infrastructure can negatively affect network performance (data collisions, interferences, etc.) [18]. Thus, network density, physical topology and communication type all determine the logical choice of topology.

Every topology has its own characteristics, which determine whether or not it is more suitable than others in terms of attributes of network functionality such as fault tolerance, connectivity, etc. This means that depending on the whole set of requirements for network functionality some topologies may have to be discarded in favour of others. Of the topologies most commonly used for interconnecting nodes in a network, the logical topologies most commonly used for A-WSNs are Tree, Chain, Partially Connected and Star (indicated as point-to-point in Figure 2). It is important to note that after 
deployment, physical topology may change due to variations in the position, reachability (due to noise, moving obstacles, etc.), available energy, malfunctioning, and task details of sensor nodes [19].

For wireless communication, the sensor node incorporates a radio module, which is chosen to suit the desired range. Sometimes, in order to increase the range, range extenders for RF transceivers are incorporated, thus providing amplification to improve both output power and LNA (Low Noise Amplification). Another option, where such devices are insufficient to cover the distance, is to include a GSM/GPRS module.

For communication between sensor nodes it is possible either to develop communications protocols on the data-linking layer using different medium access mechanisms (such as TDMA, FDMA and CSMA), or else to use different wireless communication standards and technologies (Table 1).

Table 1. Wireless communication technologies.

\begin{tabular}{|c|c|c|c|c|c|}
\hline Technology & Standard & Description & Throughput & Range & Frequency \\
\hline WiFi & $\begin{array}{c}802.11 \mathrm{a} \\
802.11 \mathrm{~b} / \mathrm{g} / \mathrm{n}\end{array}$ & $\begin{array}{l}\text { System of wireless data transmission over } \\
\text { computational networks. }\end{array}$ & 11/54/300 Mbps & $<100 \mathrm{~m}$ & $\begin{array}{r}5 \mathrm{GHz} \\
2.4 \mathrm{GHz}\end{array}$ \\
\hline WiMAX & $\begin{array}{l}\text { IEEE } \\
802.16\end{array}$ & $\begin{array}{l}\text { Standard for data transmission using radio } \\
\text { waves. }\end{array}$ & $<75 \mathrm{Mbps}$ & $<10 \mathrm{~km}$ & $\begin{array}{l}\text { 2-11 GHz } \\
\text { 3.5 GHz: Europe }\end{array}$ \\
\hline Bluetooth & $\begin{array}{c}\text { IEEE } \\
802.15 .1\end{array}$ & $\begin{array}{l}\text { Industrial specification for WPAN which } \\
\text { enables voice and data transmission } \\
\text { between different devices by means of a } \\
\text { secure, globally free radio link }(2.4 \mathrm{GHz}) \text {. }\end{array}$ & $\begin{array}{c}\text { v. } 1.2: 1 \mathrm{Mbps} \\
\text { v. } 2.0: 3 \mathrm{Mbps} \\
\text { UWB: } 53-480 \mathrm{Mbps}\end{array}$ & $\begin{array}{l}\text { Class 1: } 100 \mathrm{~m} \\
\text { Class 2: } 15-20 \mathrm{~m} \\
\text { Class 3: } 1 \mathrm{~m}\end{array}$ & $2.4 \mathrm{GHz}$ \\
\hline GSM & & $\begin{array}{l}\text { Standard system for communication via } \\
\text { mobile telephones incorporating digital } \\
\text { technology }\end{array}$ & $9.6 \mathrm{Kbps}$ & $\begin{array}{l}\text { Dependent on } \\
\text { cellular network } \\
\text { service provider }\end{array}$ & $\begin{array}{l}\text { 900/1800 MHz: } \\
\text { Europe } \\
1900 \text { MHz: USA }\end{array}$ \\
\hline \multirow[t]{2}{*}{ GPRS } & & $\begin{array}{l}\text { GSM extension for unswitched (or } \\
\text { packaged) data transmission. }\end{array}$ & 56-144 Kbps & $\begin{array}{l}\text { Dependent on } \\
\text { cellular network } \\
\text { service provider }\end{array}$ & $2.5 \mathrm{GHz}$ \\
\hline & $\begin{array}{c}\text { IEEE } \\
802.15 .4\end{array}$ & $\begin{array}{l}\text { Standard defining the physical level and } \\
\text { control of medium access of WPANs with } \\
\text { low data transmission rates. }\end{array}$ & $\begin{array}{l}20 \mathrm{Kbps}: 868 \mathrm{MHz} \text { : } \\
\text { Europe } \\
40 \mathrm{Kbps}: 915 \mathrm{MHz} \text { : } \\
\text { Americas } \\
250 \mathrm{Kbps}: 2.4 \mathrm{GHz} \text { : } \\
\text { Worldwide }\end{array}$ & $<100 \mathrm{~m}$ & $\begin{array}{l}868 / 915 \mathrm{MHz} \text { and } \\
2.4 \mathrm{GHz} \text {. }\end{array}$ \\
\hline ZigBee & $\begin{array}{c}\text { IEEE } \\
802.15 .4\end{array}$ & $\begin{array}{l}\text { Specification of a set of high-level } \\
\text { wireless communication protocols for use } \\
\text { with low-consumption digital radios, } \\
\text { based on WPAN standard IEEE 802.15.4. }\end{array}$ & $\begin{array}{l}250 \text { Kbps: } 2.4 \mathrm{GHz} \text { : } \\
\text { Worldwide }\end{array}$ & $<75 \mathrm{~m}$ & $2.4 \mathrm{GHz}$. \\
\hline
\end{tabular}

Which technology is chosen will depend on the requirements of the A-WSN it is proposed to implement, which in turn will be determined chiefly by the amount of information that has to be sent and whether images are to be sent in real time. Another requirement that has to be considered are the 
maximum distances that a communications link will have to cover, as this will determine the choice of $\mathrm{RF}$ antenna. There are several types of antenna (omnidirectional, sector type, etc.) which are chosen on the basis of characteristics such as the radiation diagram, the bandwidth needed, directionality, gain, efficiency, beamwidth and the desired polarization. In the case of sensor nodes communication is more effective with omnidirectional antennas so that the radiated power is the same in all directions. This is necessary in that the movement of the sea can cause the sensor node to move rotationally, vertically or horizontally, thus altering the original position of the buoy. The drawback of this kind of antenna is that the radiated power is more dispersed and hence the range is smaller than with more directional antennas. Directional antennas need to be properly aligned and the power channelled in a single direction; this assures more range in that direction and in some cases avoids interference with other services. One important factor that must be taken into account is the height of the antenna with respect to the flotation device supporting the node, since over long distances, visual line-of-sight is not sufficient for propagation due to attenuation and so RF line-of-sight is required. The range of these nodes is affected by that height according to Fresnel Zone theory, which tells us that for true RF line-of-sight, the Fresnel Zone radius must be less than the combined height of the antennas [20].

\subsection{Oceanographic Sensors}

There are many types of sensors for monitoring oceanographic parameters (physical, chemical and biological). The right choice of sensor depends on the requirements defined by the user and the requirements imposed by the characteristics of the area where they are to be deployed. These requirements include the measurement range within which the parameter is to be measured, the place where the sensor is to be deployed, sensitivity, linearity, accuracy, precision, resolution, measurement rate, power consumption and deployment time. The parameters most commonly measured in a marine environment and the measurement units used are shown in Table 2. In addition, depending on what sensor is used, it is essential to consider its position within the node and the depth at which it will be working. For example, to determine the temperature profile of a water column several sensors will have to be placed at different depths on the same vertical line. Figure 3 shows four commercial oceanographic sensors.

Table 2. Common oceanographic sensors.

\begin{tabular}{cc}
\hline Measured Parameter & Unit \\
\hline Temperature & ${ }^{\circ} \mathrm{C},{ }^{\circ} \mathrm{F}$ \\
Pressure & $\mathrm{mmHg}$ \\
Salinity (Conductivity) & $\mathrm{g} / \mathrm{L}$ \\
Water speed & $\mathrm{m} / \mathrm{s}$ \\
& $\mathrm{FTU}$ (Formazin Turbidity Unit) \\
Turbidity & NTU (Nephelometric Turbidity Units) \\
& $\mathrm{JTU}$ (Jackson Turbidity Unit) \\
Chlorophyll & $\mu \mathrm{LiO} \mathrm{SiO}_{2}$ \\
& $\mu \mathrm{g} / \mathrm{L}$ \\
\hline
\end{tabular}


Table 2. Cont.

\begin{tabular}{cc}
\hline Dissolved oxygen & $\mathrm{mg} / \mathrm{L}$ \\
Nitrate & $\mathrm{mg} / \mathrm{L}$ \\
$p H$ & $\mathrm{pKa}$ \\
Swell & Height: (metres) \\
& Direction:(degrees) \\
Blue-Green Algae Phycocyanin & Relative Fluorescence Units \\
Ammonium/ammonia & $\mathrm{mg} / \mathrm{l}-\mathrm{N}$ \\
Chloride & $\mathrm{mg} / \mathrm{L}$ \\
Rhodamine & $\mu \mathrm{g} / \mathrm{L}$ \\
Hydrocarbons & $\mathrm{ppm}$ \\
\hline
\end{tabular}

Figure 3. Examples of commercial sensors for oceanographic use (photographs reproduced with the owners' permission): (a) EMS-SBE_-16plus V2 SEACAT Temperature and conductivity (pressure optional) sensors; (b) NORTEK-Profiler Aquadopp (AquaPro); (c) YSI 6600V2 sonde. YSI 6136 and YSI 6025 turbidity and chlorophyll sensors; (d) AANDERAA-Oxygen Opdote 4835. Dissolved oxygen sensor.

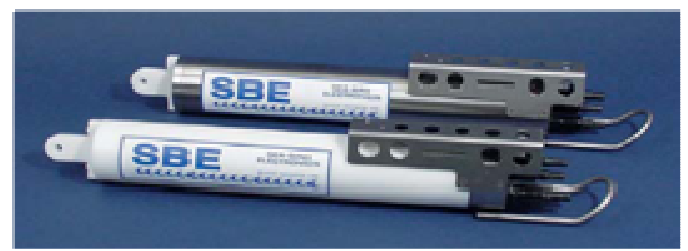

(a)

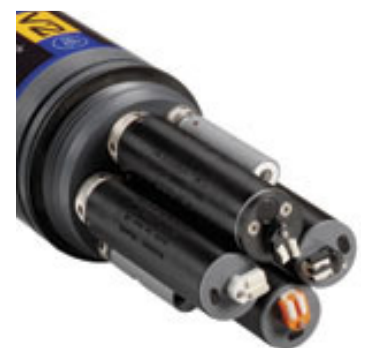

(c)

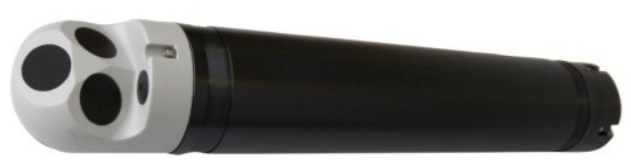

(b)

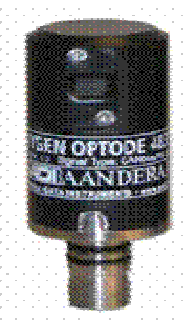

(d)

On the other hand, the sensor node may be equipped with surface sensors (Table 3), which are normally used to determine the state of the water surface or the atmosphere. These conditions may be important when setting up a sampling strategy. For example, in the event of bad atmospheric conditions the sensor node may decide to raise the sampling frequency to assure more precise monitoring of the environment. 
Table 3. Surface sensors.

\begin{tabular}{cc}
\hline Measured Parameter & Unit \\
\hline Air temperature & ${ }^{\circ} \mathrm{C},{ }^{\circ} \mathrm{F}$ \\
Air pressure & $\mathrm{mb}$ \\
Wind speed & $\mathrm{m} / \mathrm{s}$ \\
Wind direction & degrees \\
Precipitation & $\mathrm{mm}, \mathrm{inch}$ \\
Atmospheric pressure & $\mathrm{mmHg}$ \\
Relative humidity & $\% \mathrm{RH}$ \\
Solar radiation & $\mathrm{W} / \mathrm{m}^{2}$ \\
Surface salinity & $\mathrm{ppt}$ \\
Surface conductivity & $\mathrm{S} / \mathrm{m}$ \\
\hline
\end{tabular}

\subsection{Hw/Sw Solutions for Node Implementation}

Some sensor node implementations reuse commercial solutions (MicaZ ${ }^{\circledR}, \mathrm{TelosB}^{\circledR}$, Mica2 ${ }^{\circledR}$, etc.) which come with an incorporated microprocessor, and communications electronics (radio modules, antennas, etc.). These motes normally come with a set of software development tools (operating system, programming languages, reusable components, etc.) and after-sales technical support from the supplier. When the characteristics of such commercial motes are inadequate or unsuitable, sensor nodes are commonly developed from scratch using the electronic components shown in Figure 1.

The main component is a low-power microprocessor, which is the core of the platform and is responsible for managing node operation. This microprocessor must possess certain features if it is to be suitable for use with an A-WSN: its architecture, combined with some low power modes, has to be optimized to achieve extended battery life in portable measurement applications. Also, it must include several universal serial synchronous/asynchronous communication interfaces (such as UART, I2C, SPI, etc.) so that the sensors can be integrated with different types of electrical signals.

The lifetime of the network depends on the autonomy of the sensor nodes. Power is normally supplied by batteries (commonly D-cell, Lithium-ion, AA or AAA batteries), which may be supplemented by harvesting systems (solar panels, eolic generators, etc.) to prolong the useful life of the sensor node. It is sometimes necessary to adapt the voltage between the node's power supply and the rest of the components, by means of DC/DC converters.

Inclusion of a FLASH read/write permanent memory (SD, MMC, etc.) enhances the robustness of the mote by allowing data to be stored and transmitted later on when conditions permit, thus avoiding loss of information.

Another important component is a low-consumption clock operating in real time. With a clock synchronized with all the other motes, when a reading is taken from a sensor it can be stored along with the exact time of the reading. Later on, the information can be relayed to the data server, which is important when it comes to analysing the resulting data.

Sensor node software development can be done in two ways. The first and most immediate is to use specific operating systems (such as TinyOS, Contiki, MANTIS, among others) for these platforms. Although at first this way of proceeding offers advantages for the reuse of WSN libraries, it has however the drawback of limiting the hardware platforms available (e.g., due to the delay between the 
date in which a new microprocessor appears on the market until it is supported by operating systems). The second possibility is to develop the control of the sensor node using software libraries provided by the microprocessor manufacturer. These libraries allow users to manage both the communications and interfaces using well known standards. This option therefore offers greater possibilities for ad-hoc development since it covers more platforms and more interfaces. However, it requires much more experience on the part of developers and reuse is rather limited.

\subsection{Monitoring Application}

The information gathered by the sensor nodes has to be transmitted to a base station with a massive data storage system (relational databases are the commonest solution) which can also be used for the necessary studies using the existing oceanographic theoretical models. Having integrated monitoring tools makes it possible to maintain permanent communication with the sensor network deployed and access to the stored data via Internet. The information displayed by these tools usually consists of the number of nodes deployed, the parameters analysed, the geographical location of each node, the most recent data gathered by the sensor nodes, and a visualization of a data historical table.

An example of a monitoring application is shown in Figure 4, where we can see the elements that are normally incorporated: (1) a data area (left) displaying statistical data on a particular WSN subset for a user-selected time range, and (2) a two-dimensional representation of the deployment along with tools for visualizing the latest data gathered by the selected sensors in that graphic area (the example chosen uses Google Maps ${ }^{\circledR}$ and the APIs necessary to include the points of interest).

Figure 4. Example of an application for real-time monitoring of data from an oceanographic A-WSN.

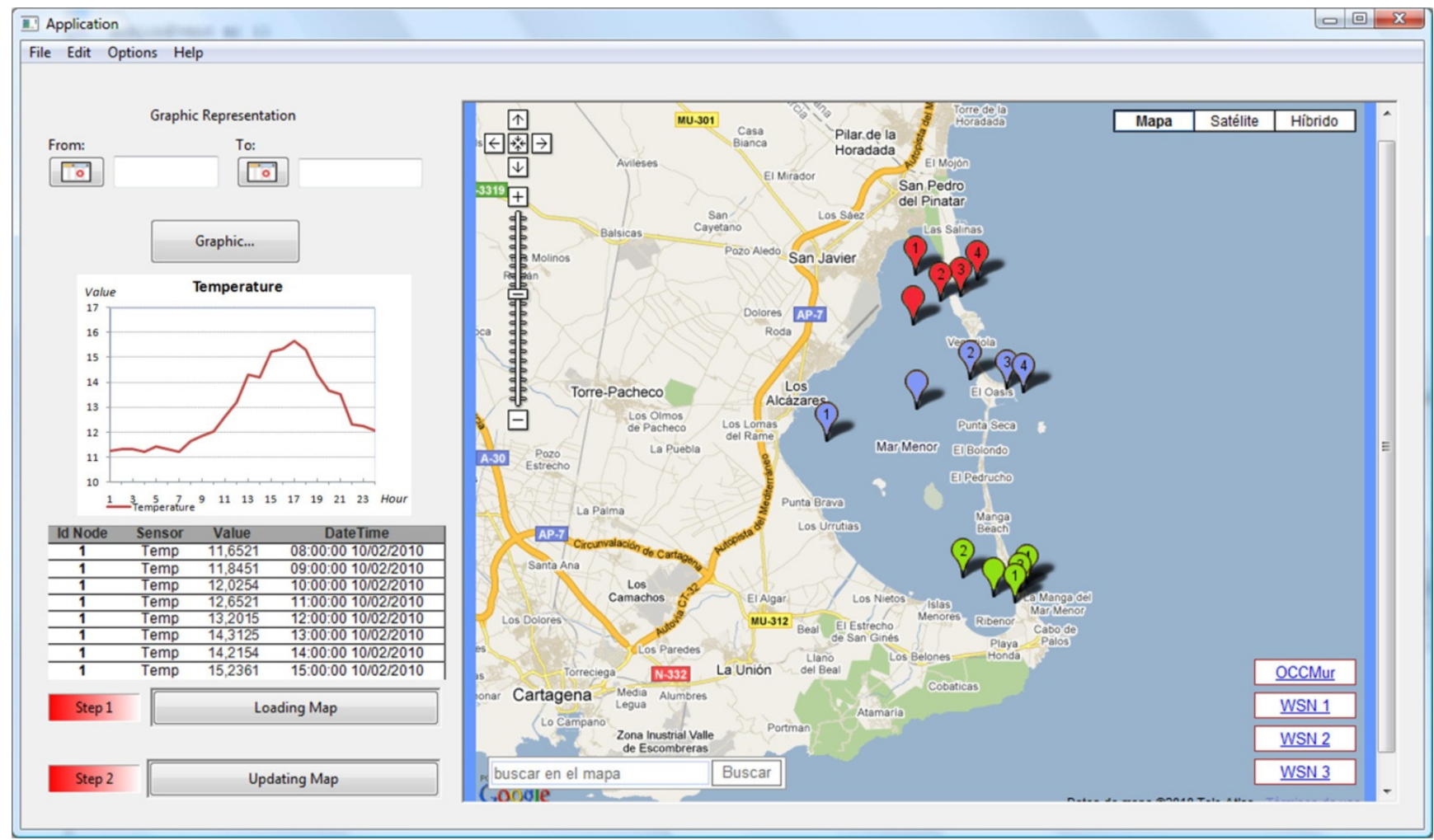




\section{Systematic Review Method}

As stated in [21], "a systematic literature review is a means of identifying, evaluating and interpreting all available research relevant to a particular research question, or topic area, or phenomenon of interest". There are several possible reasons for undertaking a systematic review of a subject of interest. The most common reasons are:

- To summarize the existing evidence relating to a piece of knowledge or a particular technology.

- To identify the gaps in an area of interest with a view to suggesting specific areas of research.

- To provide a base on which to define new lines of action on a particular subject.

In our case the main purpose of undertaking such a systematic review was to answer the following questions:

RQ1: What are the most relevant A-WSN-based oceanographic monitoring projects?

RQ2: What infrastructure is usually used in deploying A-WSNs for oceanographic monitoring?

RQ3: What is the scope of the proposals in terms of deployment, data gathered and continuity over time?

With respect to RQ1, we propose to look only at work published in the last ten years. There is very probably work published prior to A-WSNs on means of wireless monitoring of marine environments. However, we felt it reasonable to exclude these since objective RQ1 is strictly confined to A-WSN, a technology which was not available until only a few years ago. To address RQ2, we have identified and analysed the infrastructure used in the various different projects. With respect to RQ3, it is important to note that not all projects pursue the same goal. In some cases the purpose is really to find technological solutions in the field of study, while deployment serves merely to validate the results and is not a goal of the research. A systematic review must be, and seen to be, fair in order to get results and conclusions of interest and extrapolatable. In other words, a systematic review should only be undertaken on the basis of a previously-defined information search procedure or strategy. This study was carried out following the guidelines defined by [21] for the conduct of systematic reviews.

\subsection{Search Process}

The search for case studies was performed manually, analysing proceedings and journal papers since 2001. The electronic databases used were IEEE Xplore, ACM Portal, ScienceDirect, SpringerLink, CiteSeer and Google Scholar. The following three groups of search terms were used in each one:

(1)“monitoring", "environmental sensing”, "observation"

(2)"WSN", "wireless sensor networks", "sensor"

(3)“"oceanography”, "marine”, "aquatic", "coastal marine”, "oceanographic"

Each journal and conference proceedings was reviewed by three researchers (i.e., Albaladejo, Iborra and Sánchez) and any papers that addressed literature surveys of any type were identified as potentially relevant. The three named researchers later agreed on what works were representative following the pre-defined inclusion/exclusion criteria. 


\subsection{Inclusion and Exclusion Criteria}

Study selection criteria are intended to identify primary studies that provide direct evidence on the subject of the research. Peer-reviewed articles on the topic of interest, published between 2001 and 2010, were included. Articles were discarded if they presented one or more of the following characteristics:

- The article did not demonstrate the deployment of an A-WSN for oceanographic monitoring. To so demonstrate it had to furnish data on the marine environment to be monitored, include detailed photographs showing the design of the buoys used and the sensor nodes deployed in the area of interest. Another essential condition was that it states the physical parameters of interest for monitoring.

- The article placed more interest in the technology used, taking less interest in deployment and accordingly lacking detailed information thereon.

- The article had not been published or the congress/journal was not one of acknowledged prestige, either in the field of oceanography or in that of A-WSNs.

- Repeat articles on the same study or deployment. Where reports of a study had been published in several different journals, the most complete version of the study was included in the review.

Also, it was considered whether or not to consider as relevant case studies of oceanographic deployments in which isolated buoys linked to the data collection centre satellite were used. It was decided to exclude such systems as not really A-WSNs-that is, systems incorporating considerable computational capacities, power and communications resources and hence contradicting the essential idea of an A-WSN in which the sensor nodes are limited in power, computational capacities, and memory as stated in [1].

\subsection{Data Collection and Analysis}

The data extracted from each study were:

- The source (journal or proceedings) and full reference.

- Identification details of the monitoring project (name, duration, etc.).

- The organization that carried out the work (universities, research centres, etc.).

- Technical aspects concerning the A-WSN that was implemented (number of nodes, sensors incorporated, power supply system, microprocessor used, communications protocols, network range, topology, radio frequencies used and autonomy).

- Aspects relating to the deployment (year in which it was implemented, location that was monitored, time devoted to data collection and system testing).

Three researchers did the data extracting and the rest checked the resulting data. Albaladejo coordinated the data extraction and the checking, which involved all the authors of this article. In the event of disagreements, the data were discussed in detail until agreement was reached.

\section{Systematic review results}

This section summarizes the results of the study. 
Table 4. Systematic review results: Organizational aspects.

\begin{tabular}{|c|c|c|c|c|c|c|c|c|}
\hline $\mathbf{N}^{\mathbf{0}}$ & Country & Project & Organization & $\begin{array}{l}\text { Year of the } \\
\text { deployment }\end{array}$ & Period of tests & Place of tests & $\begin{array}{l}\text { Is the project } \\
\text { working? }\end{array}$ & Ref. \\
\hline 1 & USA & LakeNet & University of Notre Dame & 2005 & 10 days & St. Mary's Lake (Indiana) & No & [3] \\
\hline 2 & China & ---- & $\begin{array}{l}\text { College of Information Engineering, Key Lab of } \\
\text { Exploitation and Preservation of Coastal Bio- } \\
\text { resource, School of Biosystems Eng. and Food } \\
\text { Science }\end{array}$ & 2008 & 6 hours & Zhejiang Province & Yes & [4] \\
\hline 3 & Sweden & Klimat & $\begin{array}{l}\text { Swedish Institute of Comp. science; Umeá Marine } \\
\text { Sciences Centre, Uppsala University }\end{array}$ & 2006 & $\begin{array}{l}20 \text { hour test at } \\
\text { office and at } \\
\text { Baltic Sea }\end{array}$ & $\begin{array}{l}\text { Umeá Marine Sciences } \\
\text { Centre; Baltic Sea }\end{array}$ & No & {$[5]$} \\
\hline 4 & Australia & $\begin{array}{l}\text { Part of SEMAT } \\
\text { project }\end{array}$ & University of Queensland & 2007 & 1 week & One Mile, Moreton Bay & $?$ & {$[6]$} \\
\hline 5 & UK & SECOAS & $\begin{array}{l}\text { University College London, British } \\
\text { Telecommunications plc, Itelisys, Kent University, } \\
\text { Essex University, University of East Anglia }\end{array}$ & 2008 & 2 weeks & $\begin{array}{l}\text { Scroby snads, Norforlk } \\
\text { Coast }\end{array}$ & No & [7] \\
\hline 6 & UK & SmartCoast & $\begin{array}{l}\text { University College Cork, Dublin City University, } \\
\text { Marine Technologies Division (Ireland) }\end{array}$ & 2006 & 3 weeks & River Lee in Cork & $?$ & [8] \\
\hline 7 & USA & $\mathrm{ReCON}$ & $\begin{array}{l}\text { Great Lakes Environmental Laboratory, Thunder } \\
\text { Bay National Marine Sanctuary, Cooperative } \\
\text { Institute for Limnology and Ecosystems Research }\end{array}$ & 2006,2008 & $?$ & $\begin{array}{l}\text { Lakes Michigan, Huron and } \\
\text { Erie }\end{array}$ & $?$ & [9] \\
\hline 8 & Australia & $\begin{array}{l}\text { GBROOS } \\
\text { (Great Barrier } \\
\text { Reef Ocean } \\
\text { Observing } \\
\text { System) }\end{array}$ & $\begin{array}{l}\text { Australian Institute of Marine Science, James Cook } \\
\text { University, University of Melbourne, University of } \\
\text { Queensland, University of Sydney, Australian } \\
\text { Museum. Australian Institute of Marine Science } \\
\text { (AIMS) }\end{array}$ & $2008-2011$ & $\begin{array}{l}2 \text { years }(8.6 \\
\text { million } \\
\text { observations } \\
\text { collected) }\end{array}$ & $\begin{array}{l}\text { Great Barrier Reef, North- } \\
\text { East Coast }\end{array}$ & Yes & [10] \\
\hline 9 & China & --- & $\begin{array}{l}\text { Hangzhou Dianzi } \text { University, Environmental } \\
\text { Science Research \& Design Institute of Zhejiang } \\
\text { Province }\end{array}$ & 2008 & 1 month & $\begin{array}{l}\text { Artificial lake at HangZhou } \\
\text { Dianzi University }\end{array}$ & $?$ & [11] \\
\hline 10 & China & OceanSense & Ocean University of China & 2006 & & Costal waters of China & $?$ & {$[12]$} \\
\hline 11 & USA & GLUCOS & University of Wisconsin, Milwaukee & 2007,2008 & April to June 2008 & $\begin{array}{l}\text { Lake Michigan off the } \\
\text { Milwaukee coast }\end{array}$ & $?$ & [13] \\
\hline 12 & Spain & $\begin{array}{l}\text { CMS- } \\
\text { OOCMUR }\end{array}$ & Technical University of Cartagena & 2010 & 1 week & $\begin{array}{l}\text { Coastal Lagoon } \\
\text { Menor, Cartagena }\end{array}$ & Yes & [14] \\
\hline
\end{tabular}


Table 5. Systematic review results: Technical details.

\begin{tabular}{|c|c|c|c|c|c|c|c|c|c|}
\hline $\mathbf{N}^{\mathbf{o}}$ & $\begin{array}{l}\mathrm{N}^{0} \text { of } \\
\text { nodes }\end{array}$ & Hardware & Sensors $(*)$ & Protocol & Range & Topology & Radio & Harvesting System & Autonomy \\
\hline 1 & 8 & $\begin{array}{l}\text { MICA2/ } \\
\text { MDA300 } \\
\text { modules }\end{array}$ & $\mathrm{T}, \mathrm{DO}$, and $\mathrm{pH}$ & $\begin{array}{l}\text { Custom } \\
\text { DARPA }\end{array}$ & $\begin{array}{l}\text { All: 30m. Node } \\
\text { spacing: } 1-2 \mathrm{~m}\end{array}$ & Star & $\begin{array}{l}433 \mathrm{MHz} \text { ISM } \\
\text { band }\end{array}$ & $\begin{array}{l}2 \mathrm{D} \text {-cell batteries, a } \\
12 \mathrm{~V} \text { marine battery }\end{array}$ & Two weeks \\
\hline 2 & 8 & $\begin{array}{l}\text { MSP430F149, } \\
\text { I2C EEPROM }\end{array}$ & $\begin{array}{l}\mathrm{T}, \mathrm{pH}, \text { salinity, } \mathrm{DO} \text { and } \mathrm{COD}, \text { Air } \\
\text { temperature, Air humidity, Light } \\
\text { density; } 2 \text { node inner indexes: CPU } \\
\text { voltage, chip temperature }\end{array}$ & Zigbee & $250 \mathrm{~m}$ & $\begin{array}{l}\text { Double } \\
\text { chain }\end{array}$ & $\begin{array}{l}443 \mathrm{MHz} \text { ISM } \\
\text { radio }\end{array}$ & $\begin{array}{l}\text { Batteries }+ \text { Solar } \\
\text { energy }\end{array}$ & $\infty$ \\
\hline 3 & 2 & MSP 430F1232 & $\begin{array}{l}\mathrm{T} \text { on different heights from the water } \\
\text { surface down to the bottom }\end{array}$ & $\begin{array}{l}\text { Contiki OS; } \\
\text { GPRS }\end{array}$ & $\infty$ & $\begin{array}{l}\text { Point to } \\
\text { point }\end{array}$ & CC1100, GPRS & $\begin{array}{l}\text { Battery; future: wave } \\
\text { generator \& solar } \\
\text { cells. }\end{array}$ & Not $100 \%$ \\
\hline 4 & 10 & MicaZ & Illuminance and sensor temperature & $\begin{array}{l}\text { Custom } \\
\text { adaptaive } \\
\text { TDMA }\end{array}$ & $\begin{array}{l}\text { WSN - Server: } \\
\text { 600m. WSN: } \\
\text { 100m. Node } \\
\text { spacing: } 10 \mathrm{~m}\end{array}$ & Star & $\begin{array}{l}2.4 \mathrm{GHz} \text { ISM } \\
\text { band } \\
\text { Tx power } 50 \mathrm{~mW}\end{array}$ & $\begin{array}{l}2 \text { solar panels. The } \\
\text { energy is stored in } \\
\text { two battery packs }\end{array}$ & $\infty$ \\
\hline 5 & 10 & $\begin{array}{l}\text { PIC 18F452 } \\
\text { PIC } 16 F 76\end{array}$ & $\begin{array}{l}\mathrm{T}, \text { pressure, turbidity, tilt, } \\
\text { conductivity }\end{array}$ & $\begin{array}{l}\text { Proprietary } \\
\text { protocol. kOS }\end{array}$ & $\begin{array}{l}\text { Node spacing: } \\
\text { 150m. All: } 2 \mathrm{~km}\end{array}$ & $\begin{array}{l}\text { Multihop } \\
\text { topology }\end{array}$ & $\begin{array}{l}173.25 \mathrm{MHz} \text { ISM } \\
\text { band, GSM }\end{array}$ & 2 alkaline D-cells & Three months \\
\hline 6 & $?$ & $\begin{array}{l}\text { Tyndall mote } \\
\text { ATmega128L } \mu \mathrm{C}\end{array}$ & $\begin{array}{l}\text { T, phosphate, DO, conductivity, } \mathrm{pH} \text {, } \\
\text { turbidity, water level }\end{array}$ & $\begin{array}{l}\text { Zigbee, TinyOS, } \\
\text { IEEE } 1451\end{array}$ & $?$ & $?$ & $\begin{array}{l}2.4 \mathrm{GHz} \text { ISM } \\
\text { band }\end{array}$ & $\begin{array}{l}\text { Batteries up to } \\
560 \mathrm{mAh} ; 3 \mathrm{NiMH}\end{array}$ & $?$ \\
\hline 7 & $?$ & $?$ & $\begin{array}{l}\text { wind, air T, waves, water T and } \\
\text { current profiles, chlorophyll, } \mathrm{pH} \text {, } \\
\text { photosynthetic active radiation, DO }\end{array}$ & IEEE802.11b & $24 \mathrm{~km}$ & $?$ & $\begin{array}{l}2.4 \mathrm{GHz} \text { ISM } \\
\text { band }\end{array}$ & $\begin{array}{l}\text { Solar/batteries (lead } \\
\text { acid) }\end{array}$ & $?$ \\
\hline 8 & $>10$ & $\begin{array}{l}\text { Campbell } \\
\text { Scientific Loggers }\end{array}$ & $\begin{array}{l}\text { Conductivity, pressure, salinity, T, } \\
\text { chlorophyll/ fluorescence, turbidity. } \\
\text { Meteorological station. Nortek } \\
\text { ADCP. }\end{array}$ & $\begin{array}{l}\text { TCP/IP will } \\
\text { move to } 802.11 \\
\text { / TCP/IP }\end{array}$ & $\begin{array}{l}\text { Buoys spacing: } 1 \\
\text { km. Reef towers } \\
\text { spacing: } 2 \mathrm{~km}\end{array}$ & $?$ & $\begin{array}{l}\text { RF411 radio } \\
(920-928 \mathrm{MHz}) \\
\text { future: } 802.11 / \\
\text { WiFi }\end{array}$ & Solar/batteries & $\begin{array}{l}\text { Twelve } \\
\text { months }\end{array}$ \\
\hline 9 & 5 & $\begin{array}{l}\text { MSP430F1611, } \\
\text { CC2420, CC2430 } \\
\text { radio modules }\end{array}$ & $\begin{array}{l}\mathrm{T}, \mathrm{pH} \text {, (future: } \mathrm{DO} \text {, electrical } \\
\text { conductivity rate and } \mathrm{T} \text { ) }\end{array}$ & ZigBee & $?$ & $?$ & $\begin{array}{l}2.400-2.4835 \\
\mathrm{GHz}\end{array}$ & $\begin{array}{l}2 \text { lithium batteries or } \\
6 \text { nickel-hydrogen } \\
\text { batteries }\end{array}$ & $?$ \\
\hline 10 & 20 & TelosB & Environmental $\mathrm{T}$ and light intensity & $?$ & $300 \mathrm{~m} \times 100 \mathrm{~m}$ & $?$ & $?$ & Lithium batteries & $?$ \\
\hline 11 & 5 & $\begin{array}{l}\text { Single Board } \\
\text { Computer TS- } \\
7260\end{array}$ & $\begin{array}{l}\text { T sensor string, sonde with T, } \\
\text { conductivity, pressure, turbidity, } \\
\text { chlorophyll A fluorescence, } \mathrm{pH}, \mathrm{DO}\end{array}$ & RS-485 & $12 \mathrm{~km}$ & $\begin{array}{l}\text { Point to } \\
\text { point }\end{array}$ & $\begin{array}{l}\text { 900MHz wireless } \\
\text { modem }\end{array}$ & $\begin{array}{l}4 \text { Lithium-Ion AA } \\
\text { batteries }\end{array}$ & $\begin{array}{l}\text { One month/an } \\
\text { entire season }\end{array}$ \\
\hline 12 & 10 & $\begin{array}{l}\text { MSP430F2618, } \\
\text { CC2520 radio } \\
\text { module, CC2591 } \\
\text { range extender }\end{array}$ & $\mathrm{T}$, pressure and Nortek ADCP & ZigBee & $\begin{array}{l}\text { All: 20km. Node } \\
\text { spacing: } 2 \mathrm{~km}\end{array}$ & $\begin{array}{l}\text { Star, chain, } \\
\text { tree, mesh }\end{array}$ & $\begin{array}{l}2.4 \mathrm{GHz} \text { ISM } \\
\text { band }\end{array}$ & $\begin{array}{l}6 \text { Lithium-Ion } \\
\text { batteries } 2000 \mathrm{mAh} \\
\text { and } 2 \text { solar panels }\end{array}$ & Three months \\
\hline
\end{tabular}

(*) T: Temperature, DO: Dissolved Oxygen, COD: Chemical Oxygen Demand 


\subsection{Search Results}

Tables 4 and 5 show the results of the search procedure. Initially, twenty articles were identified with the referenced search procedure, but five of them were simplified versions of two. Moreover, three out of the twenty made no explicit mention of using A-WSNs, leaving us in doubt as to whether they had actually used such an infrastructure. Then again, one article was discarded because it was based on underwater acoustics, which falls outside the scope of this paper as noted in the introduction. Another of the articles was excluded from the survey because it did not specify whether the system had actually been implemented. In this way we identified twelve unique studies. Half of the articles were published in the proceedings of international congresses and the other half in journals of acknowledged prestige. Table 6 lists the conferences and journals identified in the survey, showing that articles of interest have been published since 2002 .

Table 6. List of conferences and journals identified by the review.

\begin{tabular}{|c|c|c|}
\hline Publication title & $\begin{array}{c}\text { Type } \\
(\mathbf{C})=\text { Conference; } \\
(\mathbf{J})=\text { Journal }\end{array}$ & Year \\
\hline Sensors & $(\mathrm{J})$ & 2002 \\
\hline $\begin{array}{l}\text { International Workshop on Sensor and Actor Network Protocols and } \\
\text { Applications }\end{array}$ & (C) & 2004 \\
\hline Spatial Sciences Qld & $(\mathrm{J})$ & 2004 \\
\hline Workshop on Real-World Wireless Sensor Networks & (C) & 2005 \\
\hline Microelectronics International & $(\mathrm{J})$ & 2005 \\
\hline Electronic Letters & $(\mathrm{J})$ & 2005 \\
\hline MTS/IEEE-OES OCEANS & (C) & 2007 \\
\hline $\begin{array}{l}\text { International conference on intelligent sensors, sensor networks and } \\
\text { information (ISSNIP) }\end{array}$ & (C) & 2007 \\
\hline $\begin{array}{l}\text { IEEE International Workshop on Practical Issues in Building Sensor Network } \\
\text { Applications }\end{array}$ & (C) & 2007 \\
\hline IEEE Conf. on Local Computer Networks & (C) & 2007 \\
\hline Environmental Engineering Science & $(\mathrm{J})$ & 2007 \\
\hline SENSEI Workshop, ICT-MobileSummit & (C) & 2008 \\
\hline MTS/IEEE Oceans & $(\mathrm{C})$ & 2008 \\
\hline Workshop for Space, Aeronautical and Navigational Electronics & $(\mathrm{C})$ & 2008 \\
\hline ICT-Mobile Summit Conference & $(\mathrm{C})$ & 2008 \\
\hline $\begin{array}{l}\text { Conf. On Embedded Networked Sensor Systems. Int. Workshop on } \\
\text { UnderWater Networks }\end{array}$ & (C) & 2009 \\
\hline Asian Control Conference & (C) & 2009 \\
\hline Sensors & $(\mathrm{J})$ & 2009 \\
\hline Computers, environment and Urban Systems & $(\mathrm{J})$ & 2009 \\
\hline
\end{tabular}




\subsection{Quality Evaluation}

To assess the quality of the data reported, it was decided to e-mail the first two authors of each publication asking them to check or complete the information gathered. We received replies to seven out of twelve such requests. In some cases the reply furnished further details of the implementation. In general terms, there were no significant discrepancies between the data gathered from the publications and the information received by e-mail.

\section{Discussion}

This section discusses the replies received to the questions that were initially put.

\subsection{What are the most Relevant A-WSN-based Oceanographic Monitoring Projects?}

Figure 5 shows the world-wide distribution of the projects selected with this systematic review. Note that they are distributed between North America, Europe, China and Australia, reflecting the global pattern of interest in advances in this field.

Figure 5. World map showing the location of the projects reviewed.

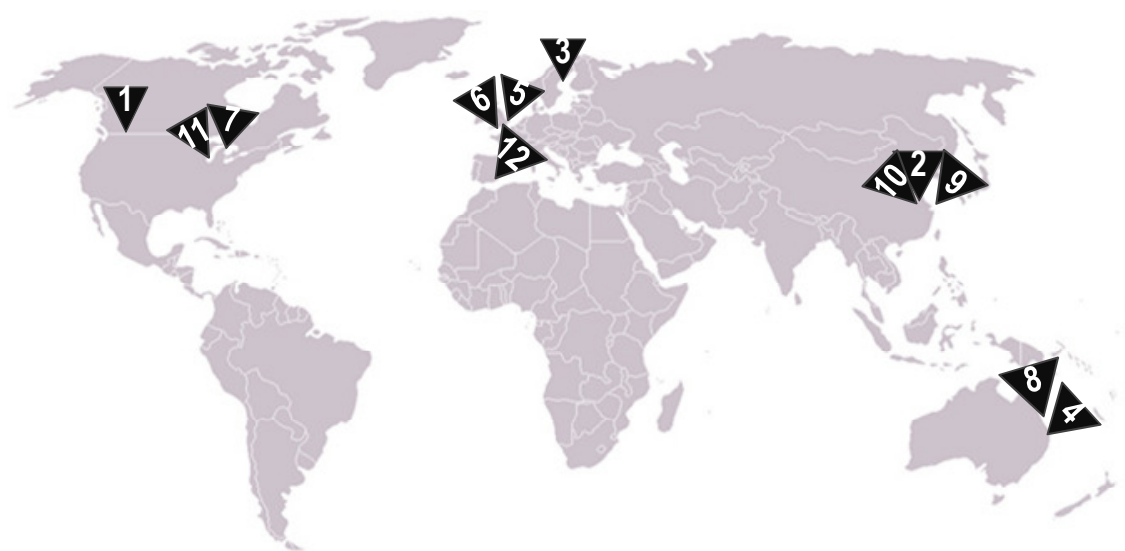

Universities took part in 11 of the 12 studies and specialized marine research centres participated in half of them.

\subsection{What is the Infrastructure usually used in Deploying A-WSNs for Oceanographic Monitoring?}

All the deployments that were implemented were for monitoring of coastal waters. The commonest parameters measured were $\mathrm{T}, \mathrm{pH}$, turbidity and Dissolved Oxygen (DO). The commonest topologies were Star and Partially Connected. The most commonly used radio frequency band is $2.4 \mathrm{GHz}$ ISM. And finally, eleven of the twelve systems used batteries, and six of the twelve considered using solar panels.

Access to and upkeep of the component elements of an oceanographic A-WSN entail a number of added difficulties on top of the ones that arise on land. It is therefore essential to define a system maintenance strategy to minimize the attendant costs and preserve proper functioning.

Maintenance of a network once in place essentially has to address three clearly distinct aspects: 
(1) maintenance of sensorization and communication elements (antennas) to prevent loss of functionality or deterioration (biofouling, calibration, orientation, etc.); (2) maintenance of the power supply (batteries, solar panels, etc.); and (3) maintenance of the network infrastructure and topology (e.g., performance degradation, synchronization of clocks, vandalism, etc.). Following are details of the survey results concerning these aspects:

1. When the buoy system is used for long-term observation, the sensors are susceptible to biofouling (microbial and algal films). Special care must therefore be taken with the quality of the instruments used, since the short-term effects of biofouling can be considerable (the quality of the measurements can sometimes be compromised in less than a week). Many techniques have been studied to prevent biofouling on materials [22]. The following need to be taken in to account when considering biofouling protection for oceanographic sensors:

a. It should not affect measurement or the environment.

b. It should not consume too much energy in order to maximize the autonomy of the monitoring system.

c. It should be reliable even in aggressive conditions.

Surface treatment based on antifouling paints is useful mainly to protect the sensor housing. UV radiation is a highly promising alternative that is non-invasive of the marine environment; however, it is not viable with the technology currently available owing to the high energy input that it requires. Another means of protection is to cover the most sensitive elements of the sensor with copper, but again the cost is high. In a word, this is a most important factor that sensor node designers need to take into account. Sensor elements normally have to be calibrated with non-portable instruments, which means that the node has to be accessed and the sensor removed for calibration in the laboratory. Maintenance operations relating to relocation of the sensor node can be performed without withdrawing the node from the network.

2. The node's power supply will require short-, medium- or long-term maintenance depending on the elements used. In normal conditions batteries limit operability to a matter of months, or even weeks [23]. It is therefore necessary to consider the use of renewable energies such as solar, eolic, wave or tidal power to significantly reduce system maintenance requirements. The most widely used is solar power because light energy is available practically constantly, and because of the accumulated experience in integrating solar panels as a supplementary energy source in A-WSN deployments [23].

3. One of the main challenges for A-WSNs as regards network topology and infrastructure is to achieve a network that functions without sacrificing originally-defined requirements in respect of performance, sensor coverage and connectivity [18]. In oceanographic applications the possibilities of perturbations in the original physical topology are heightened by the fact that the sea is a medium in constant movement (waves, tides, etc.). It is therefore desirable to use techniques that make it possible to monitor the status of the network and possible changes in its original (ideal) deployment. Several solutions have been proposed in the literature addressing these issues [24]. At the same time, considerable effort has been devoted to the design of energy efficient message delivery and data retrieval methods [25]. Theoretically, point-to-point systems are the most reliable because there is only one point of failure in the topology (the host). Moreover, the system can be made more robust by adding more hosts. However, if 
the signal range is too short it may be necessary to consider other topologies that offer wider coverage while minimizing the risks of system breakdown through the failure of a single node [19].

In all the cases reviewed, the design of the flotation device (buoy) was seen as crucial. Firstly, it is important to analyse the component elements of the node and their weights, since a given weight at a considerable distance from the buoy's line of flotation can cause instability, producing oscillations to avoid capsizing. Secondly, if such elements as batteries and electronics are close to the waterline, the space where they are contained requires more insulation. Then there is the Fresnel effect, which means that the communications antenna must be raised as high as possible to assure better robustness and quality of node communications. We identified a number of buoy implementations on the basis of the location of their components (electronics, radio, batteries, sensors) and mooring system. Figure 6 shows the most representative sensor locations identified in the survey.

Figure 6. Most representative configurations of buoys used in A-WSNs.

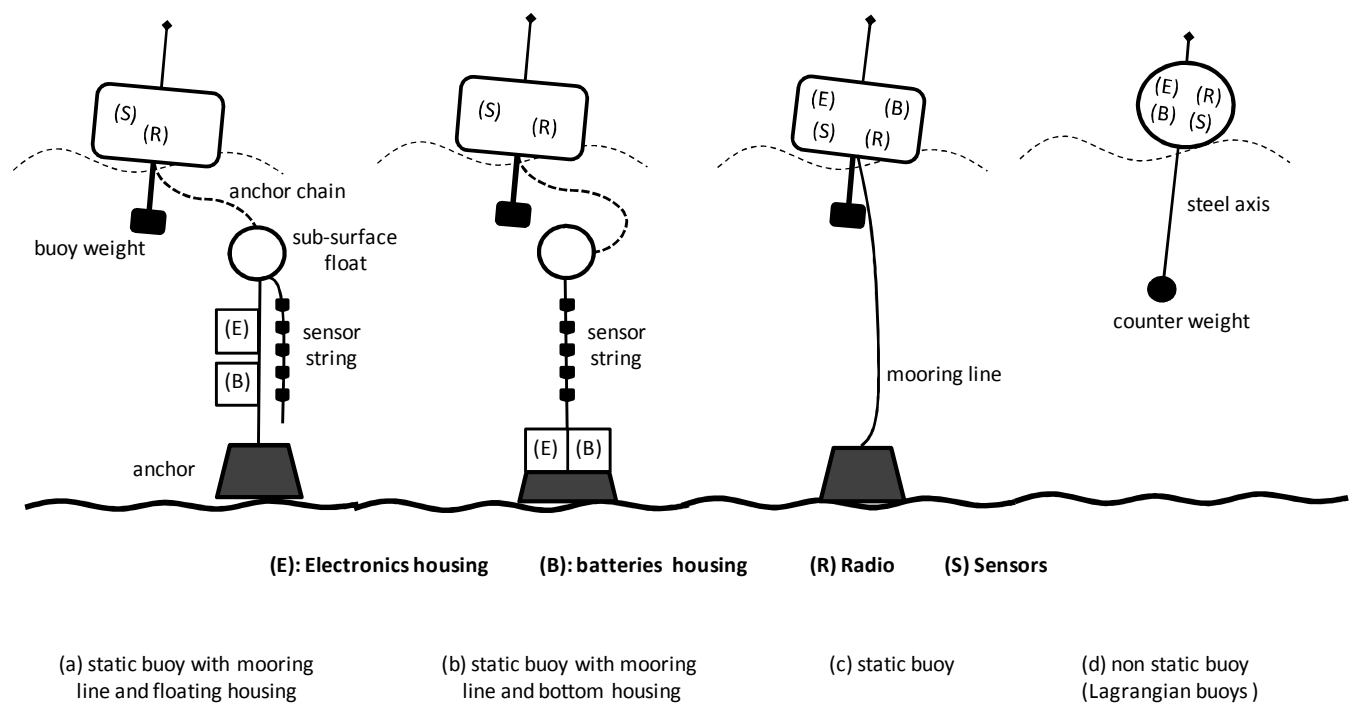

\subsection{What is the Scope of the Projects in Terms of the Deployment, the Data Collected and the} Deployment Time?

Most of the A-WSNs reviewed cover relatively small marine areas only a few kilometres across (not more than 20), and the distance between nodes is in a range of 100-250 m. As to time resolution, in most of these cases the data were sampled every 5 to $10 \mathrm{~min}$. This indicates a higher space-time resolution than can be achieved with the networks of buoys used in coastal oceanographic observatories. There, the spatial resolution is a matter of kilometres and the time resolution one of hours or days. On the other hand, coastal observatories normally cover a much larger area, as much as several hundred kilometres across.

Lastly, it is worth noting that practically all of the deployments were implemented for a short period of time, lasting at most three weeks, except in the case of number 11 (GLUCOS Project), in which monitoring was carried on for whole semesters. What this shows is that most of these deployments 
were purely experimental and that there is still a long way to go before we can have more permanent facilities.

\section{Conclusions}

The studies reviewed in this survey show that aerial wireless sensor networks (A-WSNs) are an important technological breakthrough for monitoring some oceanographic processes in which it is necessary to achieve high space/time resolutions. Also, the investment cost of deployment of an A-WSN is smaller in terms of both time and money than classic solutions like the ones used in coastal oceanographic observatories, where higher-performance devices are employed (deep-water buoys, autonomous underwater vehicles, gliders, lagrangian buoys, etc.).

From this survey it is fair to conclude that the solutions devised are generally ad-hoc ones as their design depends on various influencing factors. These factors include: the characteristics of the marine environment (deep water as opposed to shallows or coastal lagoons, climatic conditions, etc.), the time-scale of the deployment (from monitoring for a matter of weeks or months to permanent installations), the spatial scope of the deployment (large areas with low spatial resolution as opposed to smaller areas with higher resolution), and the time resolution of data collection (sampling frequencies ranging from minutes or hours to days or weeks). Because of all these different possible scenarios, designs have to be ad-hoc and have to minimize the costs of deployment and maintenance of the network. One important factor in deployment costs is the sensors that are used, which can account for up to $70 \%$ of the total initial investment. Reducing the costs of this kind of sensors is therefore a major hurdle that will have to be overcome to enable large-scale implementation of networks of this type. Other important challenges include:

- Efficient power supply systems to cover the duration of the deployment.

- Components that guarantee appropriate levels of insulation and corrosion-proofing (IP67, IP68, IP69K, etc.). It will be essential to obtain designs that minimize the number of connectors used, since these are especially sensitive to corrosion in a marine environment.

- Design of buoys with ready access to their components for maintenance and eventual dismantling. This essentially entails replacing power supply systems, replacing or calibration of the sensors used, and dismantling of the system once the monitoring task is concluded.

- Continued improvement of communications systems (antennas and radio modules) so that they are more reliable and guarantee communication between sensor nodes in adverse weather conditions.

- Buoy designs that minimize the impact of the networks deployed on the environments that are monitored. The presence of floating buoys can be a problem in areas with busy sea traffic. Also, buoys can be stolen or vandalized and therefore need to have means of protection (concealed GPS positioning systems, alarms, etc.).

The results indicate that A-WSN implementations for oceanographic monitoring are viable. Although research on the use of A-WSNs for oceanographic monitoring is still in its infancy, it points to several exciting challenges which require further interdisciplinary collaboration. 


\section{Acknowledgements}

This research was funded in part by the project "Coastal Monitoring System for the Mar Menor Lagoon", CMS (463.01-08_CLUSTER) under the Coastal Ocean Observing System of Murcia Region (OOCMUR) framework. OOCMUR has been promoted by the Spanish Murcia Region "Science and Technology Plan 2007-2010".

\section{References and Notes}

1. Akyildiz, I.F.; Su, W.; Sankarasubramaniam, Y.; Cayirci, E. Wireless sensor networks: A survey. Comput. Netw. 2002, 38, 393-422.

2. Buratti, C.; Conti, A.; Dardari, D.; Verdone, R. An overview on wireless sensor networks technology and evolution. Sensors 2009, 9, 6869-6896.

3. Seders, L.A.; Shea, C.A.; Lemmon, M.D.; Maurice, P.A.; Talley, J.W. LakeNet: An integrated sensor network for environmental sensing in Lakes. Environ. Eng. Sci. 2007, 24, 183-191.

4. Yang, H.; Wu, H.; He, Y. Architecture of wireless sensor network for monitoring aquatic environment of marine shellfish. In Proceedings of the 7th IEEE Asian Control Conference, Hong Kong, August 2009; pp. 1147-1151.

5 Voigt, T.; Osterlind, F.; Finne, N.; Tsiftes, N.; He, Z.T.; Eriksson, J.; Dunkels, A.; Bamstedt, U.; Schiller, J.; Hjort, K. Sensor Networking in Aquatic Environments: Experiences and New Challenges. In Proceedings of the 32nd IEEE Conference on Local Computer Networks, Dublin, Ireland, October 2007; pp. 793-798.

6 Cella, U.M.; Shuley, N.; Johnstone, R. Wireless Sensor Networks in Coastal Marine Environments: a Study Case Outcome. In Proceedings of the 5th International Workshop on UnderWater Networks, Berkeley, CA, USA, November 2009.

7. Fitz, S.; Gonzalez-Velazquez, A.; Henning, I.; Khan, T.; Experimental investigation of wireless link layer for multi-hop oceanographic-sensor networks. Electron. Letter. 2005, 41, pp. 13101311.

8. O’Flynn, B.; Bellis, S.; Mahmood, K.; Morris M.; Duffy, G.; Delaney, K.; O'Mathuna C. A 3D miniaturised programmable transceiver. Microelectron. Int. 2005, 22, 8-12.

9. Ruberg, S.A.; Muzzi, R.W.; Brandt, S.B.; Lane, J.C.; Miller, T.C.; Gray, J.J.; Constant, S.A.; Downing, E.J. A Wireless Internet-Based Observatory: The Real-time Coastal Observation Network (ReCON). In Proceedings of the IEEE Conference OCEANS, Vancouver, Canada, September-October 2007; pp. 1-6.

10. de Freitas, D.M.; Kininmonth S.; Woodley, S. Linking science and management in the adoption of sensor network technology in the Great Barrier Reef coast, Australia. Computer. Environ. Urban Syst. 2009, 33, 111-121.

11. Jiang, P.; Xia, H.; He, Z.; Wang, Z. Design of a water environment monitoring system based on wireless sensor networks. Sensors 2009, 9, 6411-6434. 
12. Guo, Z.; Hong, F.; Feng, H.; Chen, P.; Yang, X.; Jiang, M. OceanSense: Sensor Network of Realtime Ocean Environmental Data Observation and Its Development Platform. In Proceedings of the 3rd ACM International Workshop on UnderWater Networks, San Francisco, CA, USA, September 2008; pp. 101-105.

13. Consi, T.R.; Anderson, G.; Barske, G.; Bootsma, H.; Hansen, T.; Janssen, J.; Klump, V.; Paddock, R.; Szmania, D.; Verhein, K.; Waples, J.T. Real time observation of the thermal bar and spring stratification of Lake Michigan with the GLUCOS coastal observatory. In Proceedings of the IEEE Conference OCEANS, Quebec, Canada, September 2008; pp. 1-9.

14. Albaladejo, C.; Soto, F.; López, J.A., Iborra, A. Design of a Wireless Sensor Network for a Ocean Observing System. In Proceedings of Workshop in Automatica, Industrial Electronics and Instrumentation (SAAEI), Bilbao, Spain, July 2010; (to be published).

15. Akyildiz, I.F.; Pompili, D.; Melodia, T. Underwater acoustic sensor networks: Research challenges. Ad Hoc Network 2005, 3, 257-279.

16. Xia, F.; Tian, Y.; Sun, Y. Wireless sensor/actuator network design for mobile control applications. Sensors 2007, 7, 2157-2173.

17. Li, M.; Yang, B. A Survey on topology issues in wireless sensor networks. In Proceedings of the 2006 International Conference on Wireless Networks, Las Vegas, NV, USA, June 2006.

18. Zeng, Y.; Sreenan, C.J.; Xiong, N.; Yang, L.T.; Park, J.H. Connectivity and coverage maintenance in wireless sensor networks. J. Supercomput 2010, 52, 23-46.

19. Kim, S.; Guzide, O.; Cook, S. Towards an Optimal Network Topology in Wireless Sensor Networks: A Hybrid Approach. In Proceedings of the ISCA First International Conference on Sensor Networks and Applications, San Francisco, CA, USA, November 2009, pp. 13-18.

20. Carr, J. Practical Antenna Handbook; McGraw-Hill: New York, NY, USA, 2001; pp. 33-35.

21. Kitchenham, B.A. Procedures for Undertaking Systematic Reviews, Joint Technical Report, Computer Science Department, Keele University (TR/SE-0401) and National ICT Australia Ltd., 2004.

22. Delauney, L.; Compère, C.; Lehaitre, M. Biofouling protection for marine environmental sensors. Ocean Sci. Discuss. 2009, 6, 2993-3018.

23. Wang, X.; Ding, L.; Bi, D.; Wang, S. Energy-efficient optimization of reorganization-enabled wireless sensor networks. Sensors 2007, 7, 1793-1816.

24. Knight, C.; Davidson, J.; Behrens, S. Energy options for wireless sensor nodes. Sensors 2008, 8, 8037-8066.

25. Qiu, X.; Liu, H.; Li, D.; Yick, J.; Ghosal, D.; Mukherjee, B. Efficient aggregation of multiple classes of information in wireless sensor networks. Sensors 2009, 9, 8083-8108.

(C) 2010 by the authors; licensee MDPI, Basel, Switzerland. This article is an Open Access article distributed under the terms and conditions of the Creative Commons Attribution license (http://creativecommons.org/licenses/by/3.0/). 